\title{
Assessment of green building standards: Identifying aspects/opportunities for future improvements
}

\author{
Chakkrit Luangcharoenrat ${ }^{\mathrm{a}}$, Singh Intrachooto ${ }^{\mathrm{b}}$ \\ School of Management Science, Sukhothai Thammathirat Open University,9/9 Moo 9 Chaengwattana Rd., Pakkret, Nonthaburi 11120, Thailand \\ Faculty of Architecture, Kasetsart University, 50 Ngamwongwan Rd., Jatujak, Bangkok 10900, Thailand
}

\begin{abstract}
Social problems and environmental degradation are the result of economic development in many parts of the world. Balancing social, environment and economic is the goal of sustainable development. Many countries have developed environmental assessment standards to support sustainable development concept. This paper presents a comparative study of green building evaluation standards in both developed and developing countries to find similarities and differences in order to make future improvement on each standard to full field sustainable development concept. The comparison is done by reorganize criteria listed in those standards to match BREEAM evaluation criteria for ease of study. The study found that most building evaluation systems focuses mainly on environment and then economic while pay less attention on social side and most criteria gives higher emphasis to energy and environmental mitigation issues with "proactive" measures. For the future development of evaluation standard, social impact need to be improved and minimization of building material use need to be preventive more than reactive management.
\end{abstract}

(C) 2018 The Authors. Published by Diamond Congress Ltd., Budapest University of Technology and Economics Peer-review under responsibility of the scientific committee of the Creative Construction Conference 2018.

Keywords: Green Building Standards; Architecture; Sustainability;

\section{Introduction}

Natural resources are fundamental to human survival [1]. The development of economy and society has resulted in an unstoppable and growing consumption of natural resources and the degradation of the environment. Even though the interrelatedness among economic, social and environmental aspect of human developments is key to sustainability, it has been a huge challenge to manage. Focusing on one aspect often leads to miscalculations in other areas and "unsustainable" outcomes, sometimes disastrous [2]. Islam [3] found that long term economic growth might not benefit as much as the cost of environmental deterioration.

Architecture and construction have been a part of sustainability discourse among academics and professionals. Future buildings are being required to achieve higher performance and functionality with minimal environmental impact, while encouraging improvements in economic and social (and cultural) dimensions at local, regional and global levels [4]. The building and construction industry plays a critical role in a nation's economic and social development and is heavily responsible for the negative impact on the environment because of their large material and energy consumption, as well as their pollutant emissions throughout buildings' life cycle. Sustainable or green building [5] is "the practice of creating structures and implementing processes that are environmentally responsible and resource-efficient throughout a building's life-cycle from siting to design, construction, operation, maintenance, renovation and deconstruction". In respond to the need, many countries have developed tools to evaluate building's performance with respect to sustainable or green building concept. The Building Research Environmental 
Assessment Method (BREEAM) was the first environmental certification system created in 1990 in the Great Britain. Many countries have since followed suit with their versions of evaluation standards based on BREEAM. Each standard encourages green building through a suite of sustainability strategies that promote energy and resource efficiency, water conservation, indoor air quality and more. These green building assessment standards share many similarities in their evaluation criteria; they all include aspects such as management, water, energy efficiency, materials, waste management, site selection, pollution and indoor environment quality. The purposes of comparing 9 green building evaluation standards (for Non Residential and New Construction) are (1) to highlight the main emphases in each evaluation standard; and (2) to evaluate the distribution of criteria with regards to the three sustainability issues: environmental, social and economic; and (3) to identify aspects or opportunities for future improvement.

\section{Comparative review of green building evaluations}

To gain an understanding of previous comparative studies on green building evaluation, a total of 21 literatures published from 2006 to 2015 were reviewed. We aimed to identify: (1) which green building evaluation standards are most popular among comparative studies and (2) what the purposes of comparative study are. LEED was studied the most among standards followed by BREEAM, CASBEE, GREEN MARK, BEAM, GREEN STAR, GBTool, GBI, and ESGB. LEED and BREEAM often were selected as the basis for comparisons. CASBEE and GREEN MARK were the most studied standards from Asia. A total of 7 comparative studies focused on assessing a specific issue such as energy, passive design, lighting design, water and waste management. Other literatures were comparing existing standards in order to create a new evaluation standard of their own. Evaluation standards from the industrialized nations were studied more than those from the developing countries. It must be noted that most research on finding similarities and differences among standards did not look into weighting scores of each criterion.

\section{Research methodology}

A comparative method was used for analyzing contents in order to highlight similarities and differences among evaluation standards. This study adopted the research procedure offered by Wu et al. [7] in comparing green building standards.

\subsection{Selection of green building evaluation standards}

Wu et al. [6] and Waidyasekara et al. [7] suggested 3 criteria that could be used as a guideline for selecting green evaluation standards;

- Relevance: Some countries have more than one evaluation standard to assess different types of building. For instance, BREEAM has assessment methods for new construction, communities, existing and refurbishment building and home [8]. To fulfill objective of this paper, green evaluation standards for new construction was selected.

- Availability: Selected evaluation standards need to be available in order to get necessary detail requirements for comparison and the source can be either from the standard own websites or peer review journals.

- Measurable: Evaluation standards must have associated scores or assigned credits for each criterion, so that it is measurable for quantitative comparison.

In this study, nine (9) green building evaluation standards were pre-selected. Being the world's first evaluation standard, the Building Research Establishment Environmental Assessment Method (BREEAM) was chosen. LEED is the most widely used green building rating system in the world [9]. DGNB came from Germany, which is home of Europe's largest real estate sector. GREENSHIP, GBI, BERDE, GREEN MARK, LOTUS and TREES are all from ASEAN, which is the third largest economic in Asia and the world seventh largest [10]. All of standards are intended to be used to assess new buildings. The majority of evaluation standards assess buildings by giving points or credits when meeting criteria and adding scores into a total sum to determine rating levels. After reviewing each system with the selection guideline, four evaluation standards were chosen from developed countries and five are considered from developing countries. 


\subsection{Classification and analysis}

There are some similarities and differences in criteria among evaluation standards. For the purpose of comparison BREEAM [8] main evaluation criteria were used as the overall framework. Its criteria compose of ten main categories: (1) Management, (2) Health and Wellbeing, (3) Energy, (4) Transportation, (5) Water, (6) Material, (7) Waste, (8) Land Use and Ecology, (9) Pollution, and (10) Innovation. All other countries criteria are identified and reorganized in relation to BREEAM's main and sub-categories. Assessments that cannot be classified under one of mentioned main criteria are put under "Other". Such an organization of information allowed for analyzing the major or minor focus of each standard.

The classified main and sub criteria help identify the key distribution and correlation with the three pillars of sustainable development: environmental, social and economic. The result would reveal how the evaluation standard balances the 3 key sustainability pillars. Criteria may be applied to more than one pillar of sustainability due to their relevancies.

\subsection{Emphasize evaluation criteria}

Because each country developed green building evaluation standard for its own specific climate and cultural context, assessment criteria, relative importance of the environment categories, and documentation requirements for certification are different [7]. To identify and compare most important criteria between each evaluation standard, assigned score or weight need to be properly calculated. Wu et al. [6] used the relative significance index (RSI) to compare waste management requirements in different green building rating systems. Three (3) categories of RSI were proposed based on different scoring systems: (i) the total point without section weight, (ii) the total point with section weight and (iii) the final ranking by comparing the number of fit items with the benchmarking number [10]. Two proposed RSI were adopted and modified to suit this study.

LEED, GREENSHIP, GBI, BERDE, GREEN MARK, LOTUS and TREES are in the first category. RSI is calculated by accumulating scores without using section weights. The RSI of each criterion is calculated by the following equation, $\mathrm{Eq}(1)$.

$$
\mathrm{RSI}=\mathrm{Si} / \mathrm{TP} * 100
$$

$\mathrm{Si}=$ the assigned scores of criterion, and $\mathrm{TP}=$ the total points of the system.

BREEAM is in the second category. RSI is calculated by accumulating scores using section weights. RSI of each criterion is calculated by the following equation, Eq (2).

$$
\mathrm{RSI}=(\mathrm{Ci} / \mathrm{Cj}) * \mathrm{Wj} * 100
$$

$\mathrm{Ci}=$ the assigned credits of criterion $\mathrm{i}, \mathrm{Cj}=$ the total credits of the corresponding section $\mathrm{j}, \mathrm{Wj}=$ the weight of the corresponding section $\mathrm{j}$.

DGNB's score is comparable to RSI.

\section{Green building evaluation comparison results}

\subsection{Overview of the chosen green evaluation standards}

- BREEAM (Building Research Establishment Environmental Assessment Method) was created by BRE (Building Research Establishment) in 1990 [8]. This was the first green building evaluation standard. BREEAM for new construction consisted of 52 individual assessment issues within 10 categories

- LEED (Leadership in Energy and Environmental Design) is a voluntary green building evaluation standard that was developed in the United States by the USGBC in 2000. LEED certification for New Construction was divided into eight main categories [11].

- DGNB was created by the German Sustainable Building Council (DGNB) that was founded in 2007 and the German Federal Ministry of Transport and Construction and Urban Development. The objective was to create 
environmental compatibility, resource-friendly and economical environments that safeguard the health, comfort and performance of their users [12].

- GREENSHIP is an assessment tool that was developed by Green Building Council Indonesia (GBCI). GBCI is an independent institution, which advocates and organizes familiarization activities using principles of green, ecological, and sustainability in the planning, implementation and operation of buildings and its environment in Indonesia [13]. This tool is divided into six areas.

- The Green Building Index (GBI) is an environmental rating system for buildings developed by Malaysian Institute of Architects and The Association of Consulting Engineers Malaysia. GBI is Malaysia's first comprehensive rating system for evaluating the environmental design and performance of buildings based on the 6 main criteria [14].

- BERDE (Building for Ecologically Responsive Design Excellence) was lunched by The Philippine Green Building Council (PHILGBC) in 2010. The buildings were evaluated based on 11 main criteria [15].

- Green Mark, established by the Building and Construction Authority (BCA) of Singapore in 2005, has certified over 1,180 projects in Singapore. Green Mark is organized into 5 categories and 28 sub-categories [16].

- LOTUS is a set of market-based green building evaluation tools that was developed by the Vietnam Green Building Council specifically for the Vietnamese built environment. LOTUS evaluation system is based on various international green building rating systems [17]. LOTUS has 10 main and 55 sub evaluation criteria.

- TREES (Thailand) The Association of Siamese Architects under Royal Patronage and the Engineering Institute of Thailand under Royal Patronage jointly set up Thailand green building agency and later called Thai Green Building Institute [18]. The assessment is categorized into 8 main criteria and 51 sub evaluation criteria [19].

Table 1. RSI Comparison of criteria among green building evaluation standards

\begin{tabular}{|c|c|c|c|c|c|c|c|c|c|c|}
\hline Main Criteria & $\begin{array}{l}\text { Total } \\
\% \\
\end{array}$ & BREEAM & LEED & DGNB & GREEN-SHIP & GBI & BERDE & $\begin{array}{l}\text { GREEN } \\
\text { MARK }\end{array}$ & LOTUS & TREES \\
\hline Energy & $24 \%$ & $14 \%$ & $24 \%$ & $10 \%$ & $25 \%$ & $25 \%$ & $8 \%$ & $61 \%$ & $26 \%$ & $23 \%$ \\
\hline Health and Wellbeing & $12 \%$ & $14 \%$ & $15 \%$ & $17 \%$ & $7 \%$ & $17 \%$ & $6 \%$ & $3 \%$ & $9 \%$ & $20 \%$ \\
\hline Management & $10 \%$ & $11 \%$ & $7 \%$ & $22 \%$ & $6 \%$ & $18 \%$ & $13 \%$ & $3 \%$ & $8 \%$ & $5 \%$ \\
\hline Water & $10 \%$ & $6 \%$ & $10 \%$ & $2 \%$ & $24 \%$ & $10 \%$ & $6 \%$ & $11 \%$ & $13 \%$ & $7 \%$ \\
\hline Land Use and Ecology & $9 \%$ & $9 \%$ & $11 \%$ & $8 \%$ & $10 \%$ & $8 \%$ & $17 \%$ & $4 \%$ & $11 \%$ & $6 \%$ \\
\hline Material & $9 \%$ & $13 \%$ & $10 \%$ & $8 \%$ & $12 \%$ & $6 \%$ & $5 \%$ & $7 \%$ & $11 \%$ & $10 \%$ \\
\hline Waste & $6 \%$ & $7 \%$ & $2 \%$ & $16 \%$ & $3 \%$ & $3 \%$ & $10 \%$ & $4 \%$ & $9 \%$ & $5 \%$ \\
\hline Transport & $6 \%$ & $8 \%$ & $7 \%$ & $3 \%$ & $4 \%$ & $3 \%$ & $16 \%$ & $2 \%$ & $3 \%$ & $5 \%$ \\
\hline Pollution & $6 \%$ & $9 \%$ & $6 \%$ & $1 \%$ & $6 \%$ & $4 \%$ & $6 \%$ & $2 \%$ & $6 \%$ & $9 \%$ \\
\hline Innovation & $4 \%$ & $9 \%$ & $5 \%$ & $0 \%$ & $0 \%$ & $6 \%$ & $9 \%$ & $4 \%$ & $0 \%$ & $6 \%$ \\
\hline \multirow[t]{2}{*}{ Other } & $4 \%$ & $0 \%$ & $4 \%$ & $14 \%$ & $3 \%$ & $0 \%$ & $2 \%$ & $0 \%$ & $5 \%$ & $5 \%$ \\
\hline & $100 \%$ & $100 \%$ & $100 \%$ & $100 \%$ & $100 \%$ & $100 \%$ & $100 \%$ & $100 \%$ & $100 \%$ & $100 \%$ \\
\hline Year lunched & & 1990 & 1998 & 2008 & 2009 & 2010 & 2005 & 2012 & 2010 & 2011 \\
\hline
\end{tabular}

\subsection{Comparison of criteria in different green building evaluation standards}

A comprehensive comparison of 9 green building rating systems used in both developed and developing countries was conducted. While each of the standards emphasizes different issues and requirements for their particular locations, they share many similarities and are dedicated to promoting the construction and operation of sustainable buildings. 
RSI highlights the most important criterion in the standards - an important evidence for our comparative analysis. Table 1 presents a comparison of reclassifying mains and sub criteria to BREEAM format. There are total of 80 sub evaluation criteria spreading over 11 main categories. The outcomes of the comparison are described below:

- Management; This criterion focuses on project management issues from the initial project brief stage to design stage, procurement, building commissioning, occupancy and onto the appropriate provision of aftercare services. When comparing weighing score across 9 standards, DGNB emphasizes this criterion more than the others. GREEN MARK only gives RSI of $2.5 \%$.

- Health and Wellbeing; This criterion concerns comfort, health and safety of building occupants, visitors and others within the building as well as its surrounding. Failure to provide conditions that satisfy the majority of occupants would impact productivity due to excessive discomfort. Unhealthy buildings that would result in an increased morbidity and expose occupants to illnesses are unacceptable [20]. Thailand's TREES allocates nearly $20 \%$ of its total credits to Health and Well-being category. GREEN MARK gives far less emphasis to this criterion.

- Energy; energy used in buildings is significant and obviously the key concern with regard to global warming [20]. Due to its significant impact on the environment, energy efficiency design has the largest proportion of credits distributed amongst the environmental criteria. The specification and design of energy efficiency, systems and equipment need to support energy conservation in buildings' design and operation [9]. LEED, GREENSHIP, GIB and LOTUS allocate one fourth of its' total scores to energy issues. Buildings could earn up to $61 \%$ of the total score in GREEN MARK. Energy efficiency equipment has the highest weighting score in this energy criterion.

- Transportation; this criterion rewards thoughtful decisions about building location that encourages better access to sustainable means of transport and amenities for building users. This section emphasizes the accessibility to public transport and other alternative means of transportation that reduce car journeys and, therefore, lower congestion and CO2 emissions over the building lifespan [8]. BREEAM and LEED give higher scores on transportation criteria when comparing with other standards but still less than BERDE.

- Water; conservation of fresh water is one of the most distressing issues globally. This criterion is based mainly on an "efficiency first" approach to water conservation [21]. Reducing potable water use (internal and external) over building lifespan and minimizing losses through leakages are the main concerns of this criterion [8]. GREENSHIP gives one fourth of the total score to water-related issues. DGNB gives only minimal attention while both GBI and LEED give similar weighing scores on this water criterion of $10 \%$.

- Material; this criterion encourages steps to reduce the impact of construction materials through design, construction, maintenance and repair. As a result, embodied energy and other environmental impacts associated with the extraction, processing, transport, maintenance, and disposal of construction materials will be reduced [21]. BREEAM, LEED, GREENSHIP, LOTUS and TREES give more than $10 \%$ of their total weighting score to material-related category. The comparison shows that the evaluation standards from the developed nations are more concerned about life cycle impacts than those in the developing countries.

- Waste; this criterion encourages sustainable construction management, waste minimization during operation, maintenance and repairs [8]. By emphasizing good design and construction practices, wastes from construction and building operation could be minimized and therefore reducing the amount of waste to landfills. It recognizes measures that aim to reduce future wastes from building renovations. DGNB emphasizes and gives high scores of $16 \%$ on this criterion and on the other hand LEED gives only $2 \%$.

- Land and Ecology; the criterion emphasizes the essential relationships between buildings, ecosystems, and ecosystem services. This criterion aims to encourage sustainable land use, habitat protection and creation, and improvement of long-term biodiversity for the building's site and its surrounding land [30]. BERDE emphasizes this issue more than other standards. 
- Pollution; natural risks, harmful substances, hazardous emissions, lighting and air pollution are all deemed important in the evaluation of building environment [22]. The prevention and control of pollution and surface water run-off associated with building's location and use are addressed in this criterion. BREEAM and TREES give relatively high scores of $9 \%$ when comparing with other evaluation standards.

- Innovation; in order to encourage and recognize exemplary performance in all sustainable aspects, such as procurement strategy, design feature, management process or technological development, this criterion provides opportunities to earn scores for such endeavors. Six out of ten green building standards give scores for such an achievement.

- Others; many sub criteria cannot be categorized under above-mentioned criteria. LEED, BERDE, LOTUS and TREES provide scores for issues that respond to the local needs. DGNB give scores for design issues. Local job creation can also earn points from LOTUS.

The comparison of main criteria among the 9 green building evaluation standards has been shown in Table 1 . BREEAM, LEED have high RSI on both health \& wellbeing and energy. The majority of the evaluation standards set high priority on the energy criteria while DGNB aims at management sensibility. BERDE gives RSI of $17 \%$ to land use and ecology criteria and $16 \%$ to transportation criteria. GREEN MARK gives more than half of its' total score to energy criteria. Beside energy, GREENSHIP put heavy emphasis on water and material while giving less on waste issues. On the contrary, DGNB gives high RSI to adaptability of functions in waste criteria and only gives about $2 \%$ of its total score to water criteria. For waste criteria, 6 out of 9 evaluation standards give RSI of less than $5 \%$.

\subsection{Criteria comparison using the 3 pillars of sustainability framework}

Since the 3 pillars of sustainability (environment, social and economy) are equally vital to sustainable development, ideally, evaluation standards should evenly cover all three dimensions. This section presents the relative weights (RSI) given by the evaluation standards in relation to sustainability. The score distribution among environment, social and economy aspects implies levels of emphasis in a standard among three pillars of sustainability. Criteria were evaluated and assigned to the highest impact aspects in the sustainable concept. Some criteria may be included in multiple aspects because they straddle between boundaries. For example, criteria related to human comfort were considered as a social issue because it impacts human well being as opposed to economic [23]; at the same time energy efficient equipment belong to both environmental and economic issues because it reduced energy consumption, which affect the environment as well as cost of energy. In theory, each evaluation criteria should touch on sustainability concept equally that mean all three should have $100 \%$ RSI. Table 2 reviews RSI contribution of each green building evaluation standard toward sustainability.

After reviewing RSI of each criteria in detail, $90 \%, 79 \%$ and $43 \%$ are the average of RSI that have been allocated into the 3 pillars of sustainability, i.e., environmental, economic and social issue respectively. The RSI represents how well each standard has covered sustainability concept. DGNB has $73 \%$ in the environment-related weight criteria which is the lowest RSI among the evaluation standards. TREES, GREENSHIP and LOTUS have RSI below the average. GREEN MARK has only 17\% RSI for weight criteria relating to social issues. Eight out of 9 standards give strong emphasis on environmental issues while DGNB focus on economic.

Table 2. Comparison of RSI distribution among 3 pillars of sustainable development concept

\begin{tabular}{|c|c|c|c|c|c|c|c|c|c|c|}
\hline Environment & $90 \%$ & $88 \%$ & $92 \%$ & $73 \%$ & $93 \%$ & $98 \%$ & $80 \%$ & $98 \%$ & $92 \%$ & $93 \%$ \\
\hline Economic & $79 \%$ & $80 \%$ & $79 \%$ & $91 \%$ & $72 \%$ & $83 \%$ & $78 \%$ & $86 \%$ & $70 \%$ & $73 \%$ \\
\hline
\end{tabular}




\section{Discussions}

The balance of environmental, economic, and social aspect is the overarching goals of sustainable developments. Green building evaluation standards were created based on this drive. Even though each standard has been developed based on local conditions and environmental problems, its assessment criteria can reflect sustainable development framework. Results of this study show that the environmental dimension is the most concerned in all evaluation standards, similar to the findings by Berardi [24] and Poveda [25. However, the lack of an integrated assessment approach has led to a disproportion among the 3 dimensions of sustainability.

All green building standards have been developed with criteria to suite a country's needs and requirements to reflect the issues of greatest importance in their contexts. Regardless of the local conditions, energy efficiency remains the key measure in most standards. Increasing energy consumption and releasing $\mathrm{CO} 2$ from the construction industry affect energy efficiency requirements [26]. Importing natural gas as fuel for most power generators [27], Singapore's GREEN MARK gives $61 \%$ of RSI to energy while the average RSI on this category is $24 \%$. Meeting GREENSHIP's water conservation criterion alone can earn RSI up to $24 \%$. This implies that water problem is one of major issues in Indonesia. Water is an essential resource for any nation development and quality of life. It is recognized that any changes or decision made during design or planning phase were the most economical and effective to building performance [28]. German admitted this fact and reflected in its green building standard by giving RSI of $22 \%$ to management criteria. Exposure to natural disasters in the Philippine was ranked 3rd behind Vanuatu and Tonga respectively in the world [19]. Urbanization and environmental degradation play a significant role in increasing incidences of natural disasters [29]. These problems may have contributed to the focus on land use and ecology criteria than other criteria in BERDE.

\section{Conclusion}

This paper summarizes a comparative study of 9 green building evaluation standards, 3 from western countries and 6 from ASEAN. All selected standards were investigated to pinpoint relative significance index.

The comparison revealed that energy was given the highest weight because energy has been a major concern for most nations despite of contextual differences. Some nations such as Singapore put energy far more important than other criteria while Indonesia emphasizes water issue. With respect to the 3 pillar of sustainability, the environmental dimension has the most detailed criteria and hence receives the highest weight, followed by economic and social dimension. In addition, environmental related criteria that were categorized under energy, resources and ecology shows that the resource issue received the least weight when comparing with energy and ecology issues. Upon examining how these criteria were assessed, it was found that intention of evaluation standards were, by and large, on preventive measures, averting wastage from occurring such as using energy efficiency appliances, good design for building envelop, suitable site selection, protection of ecological features and pollution prevention. Despite the fact that building materials consume large amount of energy and released $\mathrm{CO} 2$ during manufacturing, transporting and installing [30] and its waste volume is an environmental burden, the assessments on waste minimization performance were not clearly emphasized. Notwithstanding, the waste section within evaluation standards include management aspect after waste being generated.

The finding from this comparative study suggests that to achieve the balance of three sustainability pillars, future development of green building evaluation standards need to emphasize two specific areas: firstly, include measures that recognizes social impact and secondly, change from reactive measures for material resource management to proactive measures to encourage reduction and efficient use of virgin materials. Pressure on the natural resources will increase with economic expansion and growing population. Resources are limited in relation to the growing demand; some countries run the risk of critical scarcity in the near future. Minimization material consumption by far is the most effective method [31] since it means less resource will be extracted, and therefore, lower CO2 emission during extraction, production and recycle process. 


\section{References}

[1] Stefan Giljum, Friedrich Hinterberger, Martin Bruckner, Eva Burger, Johannes Frühmann, Stephan Lutter, Elke Pirgmaier, Christine Polzin, Hannes Waxwender, Lisa Kernegger, Michael Warhurst, Overconsumption? our use of the world's natural resources, 2009. Retrieved from https://cdn.friendsoftheearth.uk/sites/default/files/downloads/overconsumption.pdf Access 12/20/2017.

[2] Strange Tracey, Bayley Anne, Sustainable development: Linking economy, society, environment, OECD Publishing, 2008. Retrieved from http://www.oecd.org/insights/sustainabledevelopmentlinkingeconomysocietyenvironment.htm Access 11/20/2017.

[3] Sardar M.N. Islam, Mohan Munasinghe, and Matthew Clarke, Making long-term economic growth more sustainable: evaluating the costs and benefits, Ecological Economics 47, 2-3 (2003) 149-166.

[4] Tarja Häkkinen, Kaisa Belloni, Barriers and drivers for sustainable building, Building Research \& Information 39.3 (2011) $239-255$.

[5] US EPA, Basic Information. Retrieved from https://archive.epa.gov/greenbuilding/web/html/about.html Access 5/20/2017.

[6] Zezhou Wu, Liyin Shen, T. W. Ann, Xiaoling Zhang, A comparative analysis of waste management requirements between five green building rating systems for new residential buildings, Journal of Cleaner Production 112 (2016) 895-902.

[7] K. G. A. S. Waidyasekara, M. L. De Silva, Comparative study of green building rating systems: In terms of water efficiency and conservation, Proceedings of the Second World Construction Symposium, Colombo, Sri Lanka (2013) 108-117.

[8] BREEAM, BREEAM UK New Construction non-domestic buildings technical manual 2014 Retrieved from http://www.breeam.com/BREEAMUK2014SchemeDocument/ Access: 5/11/2017.

[9] USGBD, New Survey Shows Top Companies Prioritize Global Green Building Rating System LEED, Retrieved from http://www.usgbc.org/articles/new-survey-shows-top-companies-prioritize-global-green-building-rating-system-leed Access: 5/20/2017.

[10] ADBI. Asean 2030: Toward A Borderless Economic Community. Brookings Institution Press, $2016 . \quad$ Retrieved from http://www.adb.org/sites/default/files/publication/159312/adbi-asean-2030-borderless-economic-community.pdf Access: 5/1/2017.

[11] USGBC, REFERENCE GUIDE FOR BUILDING DESIGN AND CONSTRUCTION Retrieved from http:/www.usgbc.org/sites/all/assets/section/files/v4-guide-excerpts/Excerpt_v4_BDC.pdf Access: 10/28/2017.

[12] DGNB, DGNB General Information: Core and Scheme Sheet Office Version 2014.

[13] GBC, GREEMSHIP New Building Version 1.1, Retrieved from http:/www.gbcindonesia.org/download/cat_view/4-greenship/5-greenshipnew-building Access: 10/23/2017.

[14] GBI, GBI Assessment criteria for NON-RESIDENTIAL NEW CONSTRUCTION (NRNC) Version 1.0 Retrieved from www.greenbuildingindex.org Access 5/16/2017.

[15] BERDE, BERDE GBRS-New Construction: Version 2.0.0 User Guide, Retrieved from http://docs.berdeonline.org/userguide/v2.0.0/berdenc/\#copyright Access 5/16/2017.

[16] BCA, BCA Green Mark for New Non-Residential Buildings Version NRB/4.1 Retrieved from https://www.bca.gov.sg/GreenMark/others/gm_nonresi_v4.1.pdf Access 10/23/2017.

[17] VGBD, LOTUS Non Residential V 1.1, Retrieved from http://www.vgbc.org.vn/index.php/pages/vgbc-publication Access 10/23/2017.

[18] A. Deboonme, P. Luengutai, Thai Green Building Institute upbeat on launch of 'TREES' initiative, The Nation Online, Retrieved from http:/www.nationmultimedia.com/business/Thai-Green-Building-Institute-upbeat-on-launch-of--30177358.html Access 5/16/2017.

[19] TGBI, Thai's Rating of Energy and Environmental Sustainability for New Construction and Major Renovation and Core and Shell Building: Version 1.1, Retrieved from http:/www.tgbi-expo.com, Access 10/23/2017.

[20] John Burnett, C. K. Chau, W. L. Lee, Green buildings: how green the label?, HKIE transactions 12.4 (2005) 1-8.

[21] USGBC, THIS is LEED: BETTER BUILDINGS ARE OUR LEGACY. Retrieved from https://www.usgbc.org/articles/leed-better-buildingsare-our-legacy Access 10/10/2017.

[22] Saleh H., Alyami, Yacine Rezgui, Sustainable building assessment tool development approach, Sustainable Cities and Society 5 (2012) 5262.

[23] A. Moro, Transnational comparison of instruments according to ecological evaluation of public buildings, ENERBUILD Final Result 6 (2011) 62-67.

[24] Umberto Berardi, Clarifying the new interpretations of the concept of sustainable building, Sustainable Cities and Society 8 (2013) $72-78$.

[25] Cesar A. Poveda, Ryan Young, Potential benefits of developing and implementing environmental and sustainability rating systems: Making the case for the need of diversification, International Journal of Sustainable Built Environment 4.1 (2015) 1-11.

[26] Pérez-Lombard, Luis, José Ortiz, Christine Pout, A review on buildings energy consumption information, Energy and buildings 40.3 (2008) 394-398.

[27] Energy profile of Singapore. Retrieved from https://editors.eol.org/eoearth/wiki/Energy_profile_of_Singapore Access 5/1/2018.

[28] Nils Larsson, An overview of green building rating and labelling systems, In Symposium on Green Building Labelling (2004) 15-21.

[29] Charlotte Benson, The economic impact of natural disasters in the Philippines (No. 99), Overseas Development Institute. 1997 Retrieved from https://www.odi.org/sites/odi.org.uk/files/odi-assets/publications-opinion-files/7026.pdf Access 1/21/2018.

[30] Ignacio Zabalza Bribián, Antonio Valero Capilla, Alfonso Aranda Usón, Life cycle assessment of building materials: Comparative analysis of energy and environmental impacts and evaluation of the eco-efficiency improvement potential, Building and Environment 46.5 (2011) 1133-1140.

[31] Chun-Li Peng, Domenic E. Scorpio, Charles J. Kibert, Strategies for successful construction and demolition waste recycling operations, Construction Management \& Economics 15.1 (1997) 49-58. 